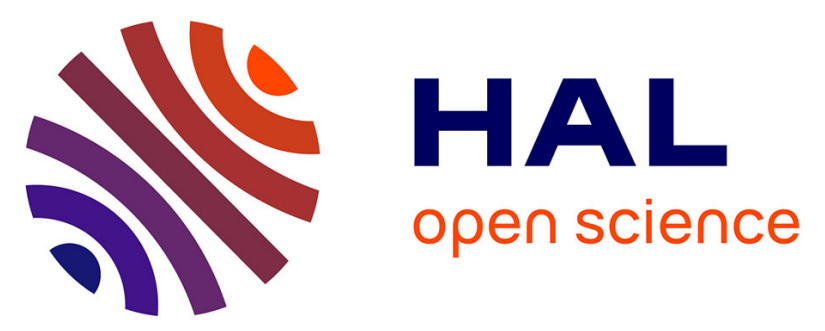

\title{
Can supercritical carbon dioxide be suitable for the green pretreatment of plant fibres dedicated to composite applications?
}

Camille François, Vincent Placet, Johnny Beaugrand, Sylvie Pourchet, Gilles Boni, Dominique Champion, Stéphane Fontaine, Laurent Plasseraud

\section{To cite this version:}

Camille François, Vincent Placet, Johnny Beaugrand, Sylvie Pourchet, Gilles Boni, et al.. Can supercritical carbon dioxide be suitable for the green pretreatment of plant fibres dedicated to composite applications?. Journal of Materials Science, 2020, 55 (11), pp.4671-4684. 10.1007/s10853-019-04293y . hal-02461189

\section{HAL Id: hal-02461189 \\ https://institut-agro-dijon.hal.science/hal-02461189}

Submitted on 16 Nov 2020

HAL is a multi-disciplinary open access archive for the deposit and dissemination of scientific research documents, whether they are published or not. The documents may come from teaching and research institutions in France or abroad, or from public or private research centers.
L'archive ouverte pluridisciplinaire HAL, est destinée au dépôt et à la diffusion de documents scientifiques de niveau recherche, publiés ou non, émanant des établissements d'enseignement et de recherche français ou étrangers, des laboratoires publics ou privés.

\section{(ㅇ)(1) $\$$}

Distributed under a Creative Commons Attribution - NonCommercial - NoDerivatives 44.0 


\title{
Can supercritical carbon dioxide be suitable for the green pretreatment of plant fibres dedicated to composite applications?
}

Camille François ${ }^{1,2,3^{*}}$, Vincent Placet $^{1 *}$, Johnny Beaugrand ${ }^{4,5}$, Sylvie Pourchet $^{2}$, Gilles Boni $^{2}$, Dominique Champion ${ }^{6}$, Stéphane Fontaine $^{3}$, and Laurent Plasseraud ${ }^{2}$

${ }^{1}$ University of Bourgogne Franche-Comté, FEMTO-ST Institute,

CNRS/UFC/ENSMM/UTBM, Department of Applied Mechanics, F-25000 Besançon, France

${ }^{2}$ ICMUB Institute, Departement of OrganoMetallic and Catalysis for Bio- and ecoCompatible Chemistry, UMR CNRS 6302, University of Bourgogne Franche-Comté, 9 avenue Alain Savary, F-21078 Dijon, France

${ }^{3}$ DRIVE EA1859, University of Bourgogne Franche-Comté, 49 rue Mademoiselle Bourgeois, F-58027 Nevers, France

${ }^{4}$ INRA, UMR 614, Fractionnement des Agro Ressources et Environnement, University of Champagne-Ardenne, 2 esplanade Roland Garros, F-51100 Reims, France

${ }^{5}$ INRA, UR1268 Biopolymères Interactions Assemblages, Site de la Géraudière, CS 71627 F-44316 Nantes, France

${ }^{6}$ UMR PAM, University of Bourgogne Franche-Comté, 1 esplanade Erasme, F-21078 Dijon, France

* Corresponding authors.

E-mail address: camille.marie.francois@gmail.com (C. François), vincent.placet@univfcomte.fr (V. Placet)

\begin{abstract}
:
This work explores the use of supercritical carbon dioxide $\left(\mathrm{sc}-\mathrm{CO}_{2}\right)$ conditions as an innovative and environmentally friendly treatment of plant fibres to optimize their performance for integration into composite materials. This study evaluates, in particular, the influence of this treatment on the mechanical, thermal, hygroscopic properties and biochemical features of industrial hemp bast fibres. Two distinct settings were tested by tuning time, temperature and pressure parameters to assess the influence of the severity of the treatment on the fibre quality. Results show that $\mathrm{sc}-\mathrm{CO}_{2}$ treatment induces an
\end{abstract}


increase in the fibre fineness and a decrease in their moisture sensitivity while maintaining their initial resistance to temperature. These changes are consistent with the measured decrease in the relative content of hemicelluloses. A significant decrease in the tensile rigidity and strength is also observed as a function of the severity of $\mathrm{sc}-\mathrm{CO}_{2}$ treatment, counterbalancing a little bit the benefits retained on the other properties.

Keywords: Hemp fibres, Supercritical carbon dioxide, Biocomposite application, Hygroscopic power, Mechanical properties

\section{Introduction}

The development of plant fibres composites (PFCs) arouses currently a significant focus in industry and academia. Indeed, inherent properties such as low density, biodegradability and high specific mechanical properties make plant fibres an attractive option for composite application [1,2]. In this way, PFCs are gaining interest and their market shares are growing in various industrial sectors, such as transport, design, acoustics, sport and leisure. Nevertheless, some of their intrinsic features, such as moisture sensitivity, and their intricate processing (including extraction from plant and transformation stages), still remain major impediments to the development of highgrade and durable composites. Anyways, several parameters can be tuned and controlled at the scale of the plant fibres themselves using efficient treatment processes, in order to improve the performance of PFCs. Indeed, even if the PFCs properties, as for all multiphasic materials, are dependent on the properties of the matrix itself, the most influential parameters are mainly related to the fibre properties, in particular their mechanical and surface properties, thermal resistance, their orientation, length, content, fineness, dispersion and affinity for the polymeric matrix which determines the adherence [3]. Plant fibre fineness is a key parameter and several studies concluded that well separated fibres are recommended for high-performance composites [4, 5]. Indeed, bundles of fibres have lower mechanical properties than single fibres [6] and the presence of the middle lamella (in bundles) can induce an early damage in composite [7]. The hydrophilic character and the hygroscopy of the plant fibres represent also one of the main barrier for their use in composites. Indeed, the moisture sensitivity of the fibres can limit the resistance at the interface with the matrix $[8,9]$. Fibre water uptake 
or desorption in composite when exposed to moisture variations may cause significant swelling and shrinkage and thus irreversible damages within the composite material, reducing both the dimensional stability and the durability of PFCs. It can also induce a degradation of the fibres themselves by biological agents including mainly bacteria and fungi. The hydrophilic character can also alter the wetting properties, and thus depending on the matrix, and in particular on its polarity, impede the impregnation of plant fibre reinforcements during the composite fabrication [10]. Hydroxyl groups present in pectic substances and hemicellulose are the main components that contribute to the fibres' moisture sensitivity. Therefore, their removal can alleviate the fibre hygroscopy and thus enhance their properties for successful use in PFCs.

So, fibre individualisation and the reduction of their moisture sensitivity while retaining good thermal and mechanical performance are the main challenge when preparing plant fibres for composite applications.

Therefore, numerous studies were and are still conducted to facilitate fibre extraction and individualization, modify, enhance, and tune their properties to meet as best as possible the composite application requirements. This is generally achieved using physical, chemical and/or enzymatic treatments. Liu et al. [3] proposed recently an excellent review of the pre-treatments envisioned and developed up to now for hemp bast fibres. It critically and comprehensively assesses the treatment processes and data available for producing well separated hemp bast fibres having optimal chemical and physical properties for best mechanical and durability properties of PFCs. It also turns out that one of the major remaining challenges is to develop a pre-treatment process that succeeds in enhancing the fibre properties while retaining an optimal cost and minimising its environmental footprint.

In such a context, the use of supercritical fluids could be an efficient process. Supercritical carbon dioxide $\left(\mathrm{sc}-\mathrm{CO}_{2}\right)$ is a fluid state of carbon dioxide where it is held at or above its critical point $\left(31^{\circ} \mathrm{C}-73.8 \mathrm{bar}\right)$. In its supercritical state, carbon dioxide $\left(\mathrm{CO}_{2}\right)$ constitutes a "green" solvent with specific properties, recyclable and non-toxic, while remaining inexpensive [11]. Combining a vapour-like viscosity, a liquid-like density and a high level of diffusion, $\mathrm{sc}-\mathrm{CO}_{2}$ treatment is well-known and particularly developed in the industrial sector [12]. The $\mathrm{sc}-\mathrm{CO}_{2}$ can be used as solvent for dry cleaning and for extraction for instance. For textile treatments, sc- $\mathrm{CO}_{2}$ have been applied on natural fibres such as cotton and showed a degradation of the tensile strength 
at $160^{\circ} \mathrm{C}$ and 300 bar [13]. It was gaining popularity among coffee manufacturers looking to remove the caffeine. In more recent applications, this treatment has been employed to extract 2,4,6-trichloroanisole from cork stoppers, responsible for the "corked" taste that spoils wines [14].

To the best of the author's knowledge, and on the basis of this open bibliography, it appears that this process, quite extensively studied and used for the lignocellulosic fractionation pretreatment for biorefinery [15] or for molecule extraction [6-7], was rarely envisioned and used for the preparation and treatment of plant fibres for material applications. Only Guttiérrez et al. [18] studied the effect of sc- $\mathrm{CO}_{2}$ treatment on Curauá fibre properties (Ananas lucidus). Their results exhibit a partial extraction of lignin and a fibrillation of the fibres induced by sc- $\mathrm{CO}_{2}$ treatment. Recently, a Chinese research team filed a patent describing a treatment for hemp fibres combining $\mathrm{sc}-\mathrm{CO}_{2}$ and conventional chemical treatments [19]. The patent describes a degumming method of hemp fibres that can significantly reduce lignin and other non-cellulosic components and more generally improve processing and quality of hemp fibre products. These preliminary results showed that the treatment of plant fibres with supercritical $\mathrm{CO}_{2}$ deserved to be deepened. So, the aim of this present work was to evaluate the potentialities and impacts of such a treatment for the preparation of hemp fibres for composite applications. It involves various and complementary analysis techniques taking into account several physicochemical parameters. Two treatments involving two distinct sets of pressure and temperature, and located in the supercritical area of $\mathrm{CO}_{2}$ have been investigated and compared. The first one, TF-1, is performed at $40^{\circ} \mathrm{C}$ and 75 bar (just above the critical point), and the second, more severe, TF-2, is carried out at $129^{\circ} \mathrm{C}$ and 149 bar. The influence of these treatments was evaluated by the examination of the biochemical, physical and mechanical properties of the fibres.

\section{Materials and methods}

\subsection{Plant materials}

Hemp fibres (Cannabis sativa L., cultivars 'Fedora 17') used to conduct this study came from the same batch as was used in Placet et al. [20]. They were cut and harvested in September 2013. These operations were carried out on a short time with the objective of minimizing the retting phase. The straws were then processed using an industrial process that includes breaking and scutching of the stalks. The extracted raw fibres were 
delivered in a disordered form which contains both single and technical hemp fibres with a very low content of shives.

\section{$2.2 \mathrm{sc}-\mathrm{CO}_{2}$ treatment}

The sc- $\mathrm{CO}_{2}$ treatment process was carried out using a home-made batch reactor in stainless steel manufactured in Dijon, France. This reactor, with a total capacity of 100 $\mathrm{cm}^{3}$, has a closure system using six screws and is equipped with a Teflon seal ensuring leak tightness. It has an upper limit of 250 bar overpressure.

Hemp fibres were subjected to two types of $\mathrm{sc}-\mathrm{CO}_{2}$ treatments. The first one, named TF-1 is performed at $40^{\circ} \mathrm{C}$ under a pressure of 75 bar, so just above the critical point in the supercritical state. The second one, TF-2 is carried out under high temperature and pressure conditions $\left(129^{\circ} \mathrm{C}-149\right.$ bar). Technical fibres were first placed in the reactor and then conditioned under vacuum during 4 hours. The system was then filled with argon gas in order to keep the fibres under inert atmosphere and to purge the injector prior to introducing $\mathrm{CO}_{2}$. The reactor was placed in ice bath so that sufficient amount of $\mathrm{CO}_{2}$ was supplied for the experiment. The amount of $\mathrm{CO}_{2}$ injected in the reactor was measured and controlled using a balance. The reactor, containing fibres and $\mathrm{CO}_{2}$ was equipped with a heating sleeve whose temperature program was registered using the software LabVIEW®. When the set temperature was reached, the experiment began and lasted 17 hours. After that, the reactor was promptly depressurized to allow its opening and characterization of fibres. The quantity of hemp fibres introduced within the reactor was about 70-80 mg for each test. The parameters used for each test are described in Fig. 1. 


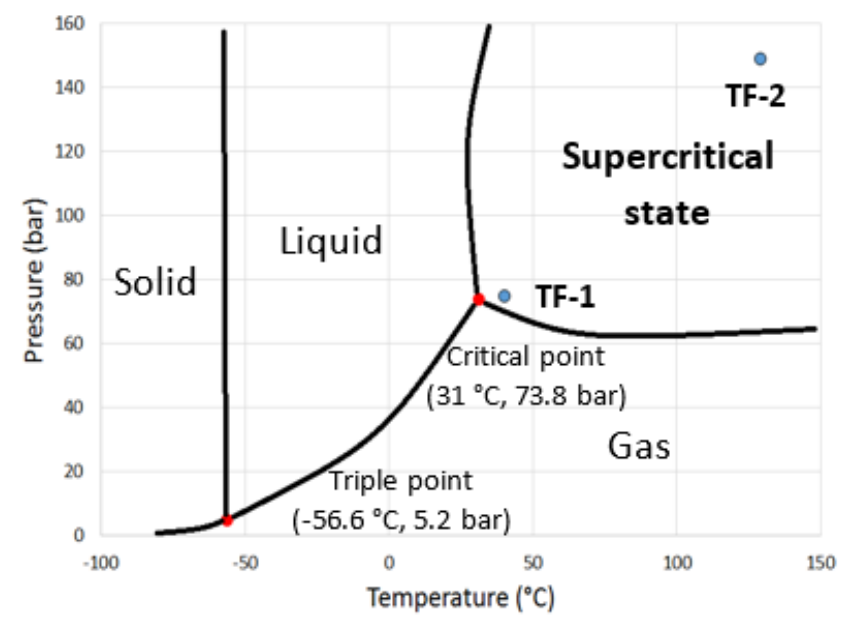

\begin{tabular}{|l|l|l|}
\hline & TF-1 & TF-2 \\
\hline Temperature $\left({ }^{\circ} \mathrm{C}\right)$ & 40 & 129 \\
\hline Pressure $($ bar $)$ & 75 & 149 \\
\hline Mass of $\mathrm{CO}_{2}(\mathrm{~g})$ & 33 & 34 \\
\hline Mass of fibres $(\mathrm{g})$ & 3.8 & 3.8 \\
\hline Duration $(\mathrm{h})$ & 17 & 17 \\
\hline
\end{tabular}

Figure 1 Phase diagram of $\mathrm{CO}_{2}$ and parameters for the two types of treatment

2.3 Fibre characterization techniques

\subsubsection{Scanning electron microscopy (SEM)}

Observations of treated and untreated hemp fibres were realized on Hitachi VP-SEM SU1510 equipment (Hitachi High Technologies America). The back-scattered electrons (BSE) imaging mode was used to obtain the images. The images were saved with magnification $\times 500$, acceleration voltage of $15 \mathrm{kV}$ and vacuum pressure equals to 30 Pa.

\subsubsection{Thermogravimetric analyses}

Thermogravimetric analyses were performed on a TA Instruments TGA Q600 thermoanalyzer using platinum pans. Samples (5-10 $\mathrm{mg}$ ) were heated from room temperature to $800{ }^{\circ} \mathrm{C}$ at a rate of $20{ }^{\circ} \mathrm{C} \cdot \mathrm{min}^{-1}$ under air flow $\left(100 \mathrm{~mL} \cdot \mathrm{min}^{-1}\right)$. Weight loss percentages were recorded using the TA Universal Analysis 2000 software.

\subsubsection{Bio-chemical analyses}

Prior to lignin and carbohydrate content determinations, sc- $\mathrm{CO}_{2}$ treated technical fibres (TF-1 and TF-2) and non-treated fibres (NTF) were powdered for the purpose of sample homogenisation. Thus, $3 \mathrm{~g}$ of each sample type was cut with scissors and then milled in a centrifugal grinding mill (Retsch MM2000 Mill). The lignin contents were determined using the Klason method well detailed in [20]. Carbohydrate identification and quantification were performed using HPAEC (ICS-5000+ DC, Dionex) following a 
procedure fully described in [20]. Analyses were performed in three independent assays for TF-1, TF-2 and NTF.

\subsubsection{Water uptake}

The water vapour sorption isotherms were measured using to the Dynamic Vapour Sorption (DVS) technique. The equipment (Surface Measurement Systems) used for these studies measures the uptake and loss of water gravimetrically using a microbalance $(\mathrm{Cahn})$ with a mass resolution of $\pm 0.001 \mathrm{mg}$. The partial pressure of water vapour around the sample is controlled by mixing saturated and dry carrier gas streams using electronic mass flow controllers. The samples, each weighing between 6 and $8 \mathrm{mg}$, were equilibrated under various humidity environments, from $0 \%$ to $90 \%$ of relative humidity $(\mathrm{RH})$ in air-tight containers. After a decrease to the dried state $(0 \%$ $\mathrm{RH})$, the $\mathrm{RH}$ was increased incrementally by steps of $2 \% \mathrm{RH}$ from 0 to $10 \% \mathrm{RH}$, and by steps of $10 \% \mathrm{RH}$ from $10 \%$ to $90 \% \mathrm{RH}$. It was then reduced again incrementally to $0 \%$ $\mathrm{RH}$ by steps of $15 \% \mathrm{RH}$. The temperature $\left(20^{\circ} \mathrm{C}\right)$ was kept constant during the entire experiment. The first conditioning step with an equilibrium at $0 \% \mathrm{RH}\left(120 \mathrm{~min}\right.$ at $40^{\circ} \mathrm{C}$ and $180 \mathrm{~min}$ at $20^{\circ} \mathrm{C}$ ) ensures similar conditioning for each batch of analysed fibres. For each RH step, a dwell at RH was maintained during 3 hours, except for the last one (90 $\% \mathrm{RH}$ ) which lasted 5 hours. These times were determined using preliminary experiments. They represent the time necessary to reach the moisture equilibrium (characterised by a variation of the mass lower than $0.003 \%$ on a time interval of one minute). The running time, target $\mathrm{RH}$, actual $\mathrm{RH}$ and sample weight were continuously recorded with a sampling rate of $0.05 \mathrm{~Hz}$. The water content is defined as the fraction determined by dividing the mass of water that fibres contain by the fibre dry mass. The adsorption behaviour of hemp fibres was analysed by fitting experimental data with the Hailwood Horrobin (H-H) model [21] based on Equation 1.

$$
\frac{H}{M}=A+B H-C H^{2}
$$

Where $\mathrm{M}$ is the moisture content at a given percentage of relative humidity $\mathrm{H}$. A, B and $\mathrm{C}$ are constants. It is also possible to calculate equilibrium constants $\left(\mathrm{K}_{1}\right.$ and $\left.\mathrm{K}_{2}\right)$ and molecular weight of cell wall polymer per sorption site (W) using these parameters which are estimated by minimization algorithms. The M0 parameter, equal to $1800 / \mathrm{W}$, was also calculated. 


\subsubsection{Tensile characterization on hemp fibres}

Some fibres (single fibres and possibly small bundles of fibres) taken from the disordered raw technical fibres were tensile tested before and after treatment. Approximately 40 fibres with a mean diameter of about $20 \mu \mathrm{m}$ were tested following the procedure fully described in [20], except for the crosshead displacement rate and the controlled relative humidity that were set at $10 \mu \mathrm{m} \cdot \mathrm{s}^{-1}$ and of $32 \% \pm 3 \%$ in this study. Considering the dependence of the tensile strength and stiffness of hemp fibres on their diameter [22], and to ensure a meaningful comparison, tests were performed on elementary fibres having an average diameter of approximately $20 \mu \mathrm{m}$. The mean value and standard deviation of these tensile properties were computed for each batch of fibres. A statistical analysis was also performed using EasyFit ${ }^{\circledR}$. The best distribution function for each property was identified using Anderson-Darling criterion. The Young's modulus and the ultimate strength are described with a $\operatorname{lognormal}(\operatorname{LogN}(\mu$, 2)) distribution and the strain at failure is defined by a Weibull (Weibull $(\alpha, \beta)$ ) distribution (Eqs. 1, 2).

$$
\begin{gathered}
\log N(\mu, \lambda): f(x)=\frac{1}{x} \frac{1}{\lambda \sqrt{2 \pi}} \\
W e i b u l l(\alpha, \beta): f(x)=1-e^{-\left(\frac{x}{\beta}\right)^{\alpha}}
\end{gathered}
$$

\subsubsection{Fibre fineness}

The fibre width distribution for each batch was measured via an automated apparatus MorFi (Techpap, Grenoble, France). The protocol used to do these measurements is fully described in [20]. Over 2,000 fibre elements were measured for each batch.

\subsubsection{Powder X-ray diffraction (XRD)}

The NTF and TF-2 samples were analysed using X-ray diffraction according to the same procedure as the one fully described in [20]. The amount of crystalline cellulose was determined using the Rietveld method.

\subsubsection{Analysis of VOCs by SPME and GC-MS}


Solid phase microextraction (SPME) was used to analyse the volatile organic compounds (VOCs) extracted from the treatment of the hemp fibres with sc- $\mathrm{CO}_{2}$. A silica-based SPME fibre coated with divinylbenzene/carboxen/plydimethylsiloxane (DVB/CAR/PDMS, 50/30 lm, Stableflex) from Supelco to adsorb VOCs extracted during $\mathrm{sc}-\mathrm{CO}_{2}$ treatment VOCs present on SPME fiber were analyzed in gas chromatography coupled to a mass spectrometer (GC-MS).

\section{Results}

\subsection{Fibre surface morphology}

SEM images (Fig. 2) indicate an effect of $\mathrm{sc}-\mathrm{CO}_{2}$ treatment at the microscopic scale. The image at the left of the Fig. 2 shows a strong surface roughness and a lot of pectic residues and impurities on the surface of the untreated hemp fibre bundles while the image at the right reveals clean fibres with very few residual impurities. The $\mathrm{sc}-\mathrm{CO}_{2}$ treatment also makes the cellulose macrofibrils apparent. Thus, the treatment seems to improve the individualisation of the fibres within the same bundle.
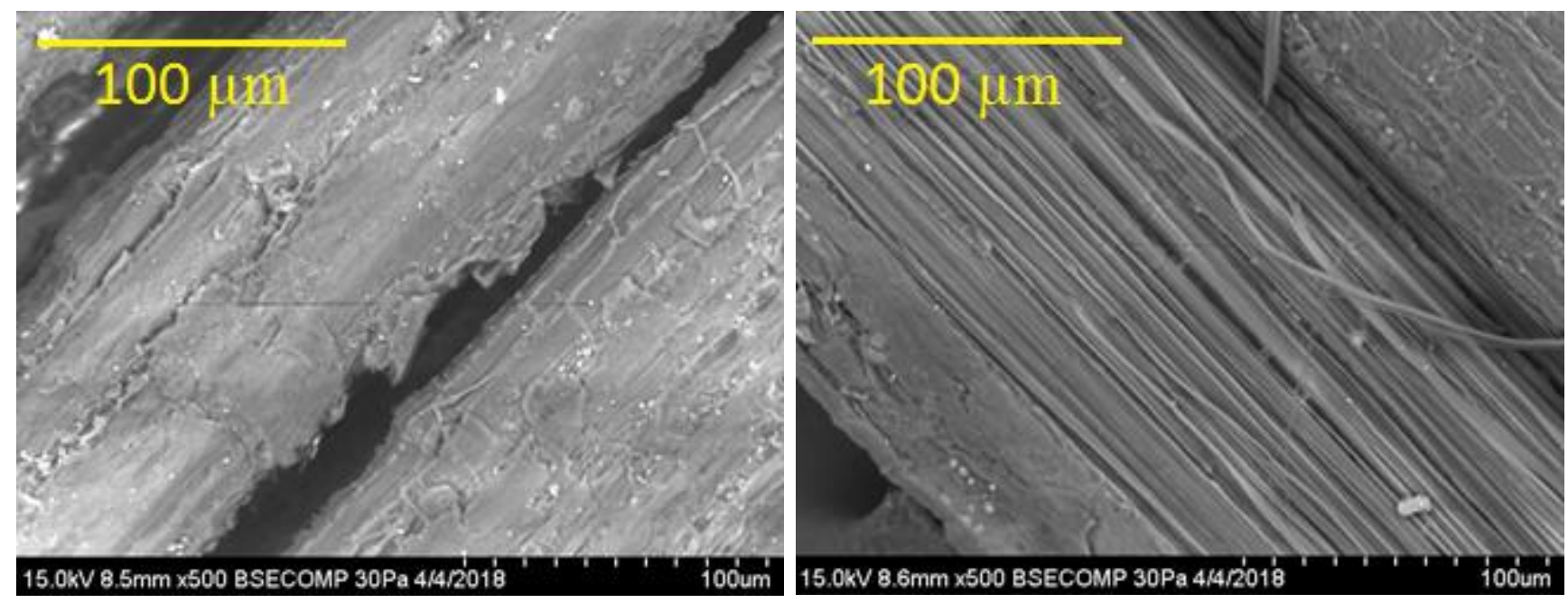

Figure 2 SEM images of NTF (left) and TF-2 (right)

\subsection{Fibre fineness}

The impact of the sc- $\mathrm{CO}_{2}$ treatment on the fibre fineness was quantified by measuring the width of the fibre elements in both batches, TF-1 and TF-2. These results were then compared with those obtained on non-treated fibres (NTF) and for which the results were previously published in [20]. The fibres treated in this work were taken in the same 
batch than the fibres tested and characterised in [20]. Fig. 3 shows the histogram distribution of the fibre width for each batch. For NTF, we observed a monomodal distribution of fibres' width centred on the intervals 53-69 $\mu \mathrm{m}$. In contrast, results from TF-1 and TF-2 revealed a bimodal distribution. It is characterized by the presence of two main populations. The first population was defined with an average width of 5-21 $\mu \mathrm{m}$ and the second one was around $70 \mu \mathrm{m}$. We observed a significant decrease in the average width of fibre elements using the sc- $\mathrm{CO}_{2}$ treatment. In fact, the average width is $56.2 \pm 1.5 \mu \mathrm{m}$ for NTF, $35.8 \pm 1.6 \mu \mathrm{m}$ for TF-1 and $33.6 \pm 3.7 \mu \mathrm{m}$ for TF-2. The typical width ranged between 5 and $150 \mu \mathrm{m}$ and a lognormal distribution offered the more realistic fit to the width measurements. A general shift of the distribution of the TF-1 and TF-2 widths to the left (to the smaller diameters) compared to the NTF can be observed. For NTF, $26.5 \%$ of the elements have a diameter between 5 and $37 \mu \mathrm{m}$, whereas $37.6 \%$ and $43 \%$ for TF-1 and TF-2 respectively. This width range represents the typical elementary primary hemp fibres. Regarding the different types of treatment, no significant difference can be observed between both treated fibre batches in the selected pressure and temperature conditions.

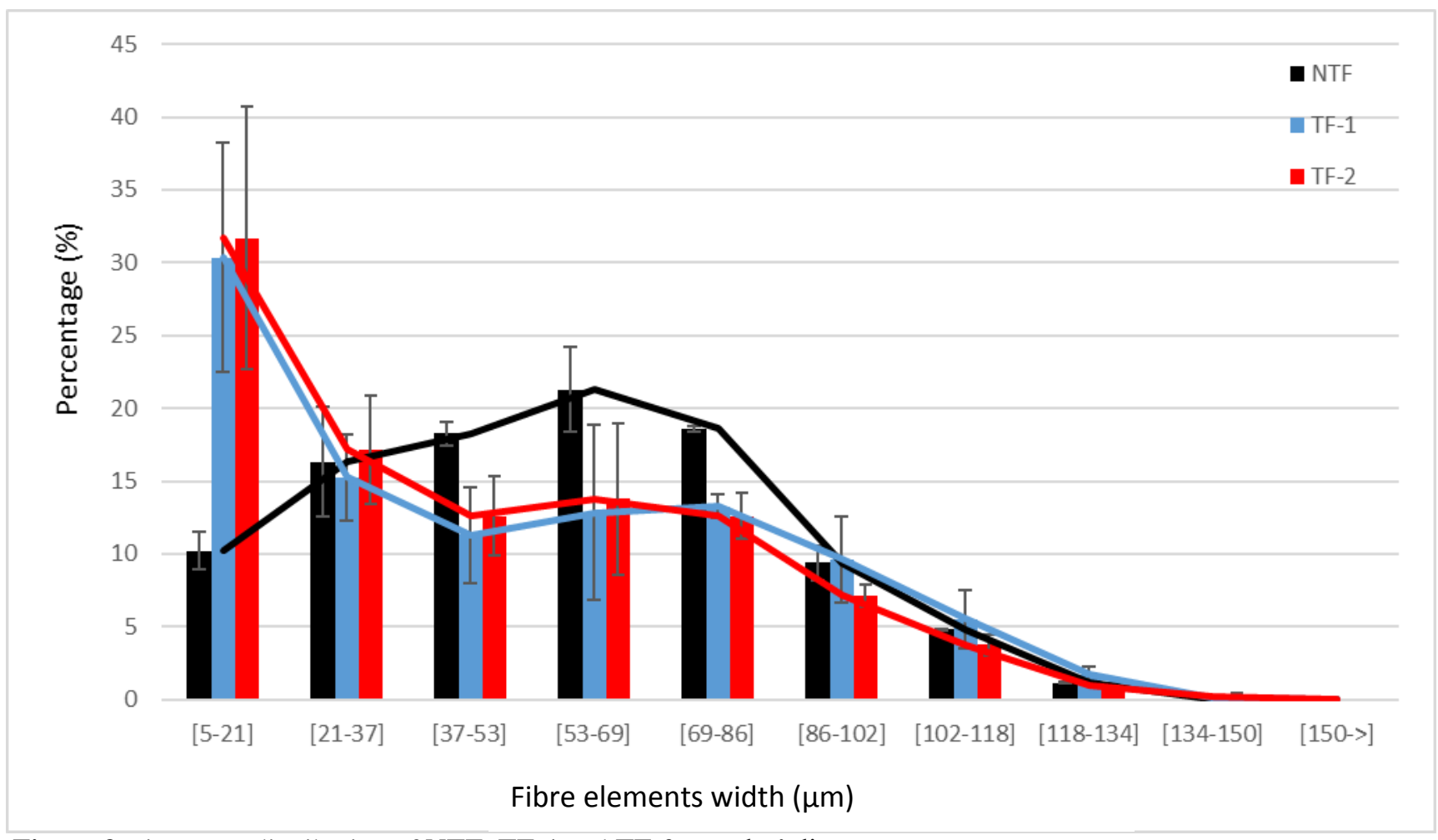

Figure 3 Histogram distribution of NTF, TF-1 and TF-2 samples' diameters 


\subsection{Thermal properties}

The influence of the sc- $\mathrm{CO}_{2}$ treatment on the thermal properties of the fibres was also investigated using thermogravimetric analysis. Samples from each batch (NTF, TF-1 and TF-2) were characterized. The thermograms represent the weight loss of the fibres as a function of increasing temperature (Fig. 4). As already depicted in the literature, the obtained curves show three stages. The first one exhibits a peak around $60^{\circ} \mathrm{C}$ that corresponds to the evaporation of the water (DTGA curves). The second stage is generally attributed to the degradation of the majority of hemicelluloses, celluloses and pectin degrade between $200^{\circ} \mathrm{C}$ and $400^{\circ} \mathrm{C}$. The third peak (around $450^{\circ} \mathrm{C}$ ) is characteristic of the degradation of the lignin and of the degradation of the formed byproducts [23]. The results showed that the treatment with $\mathrm{sc}-\mathrm{CO}_{2}$ does not induce significant variations on the thermal degradation profiles, except for the third peak on the DTG curve. A decrease is observed for TF-1 and TF-2 compared with NTF. This result, in agreement with the results obtained by Gutiérrez et al. [18] on curaua fibres, can be attributed to the partial extraction of lignin from fibres during the $\mathrm{sc}-\mathrm{CO}_{2}$ treatment.

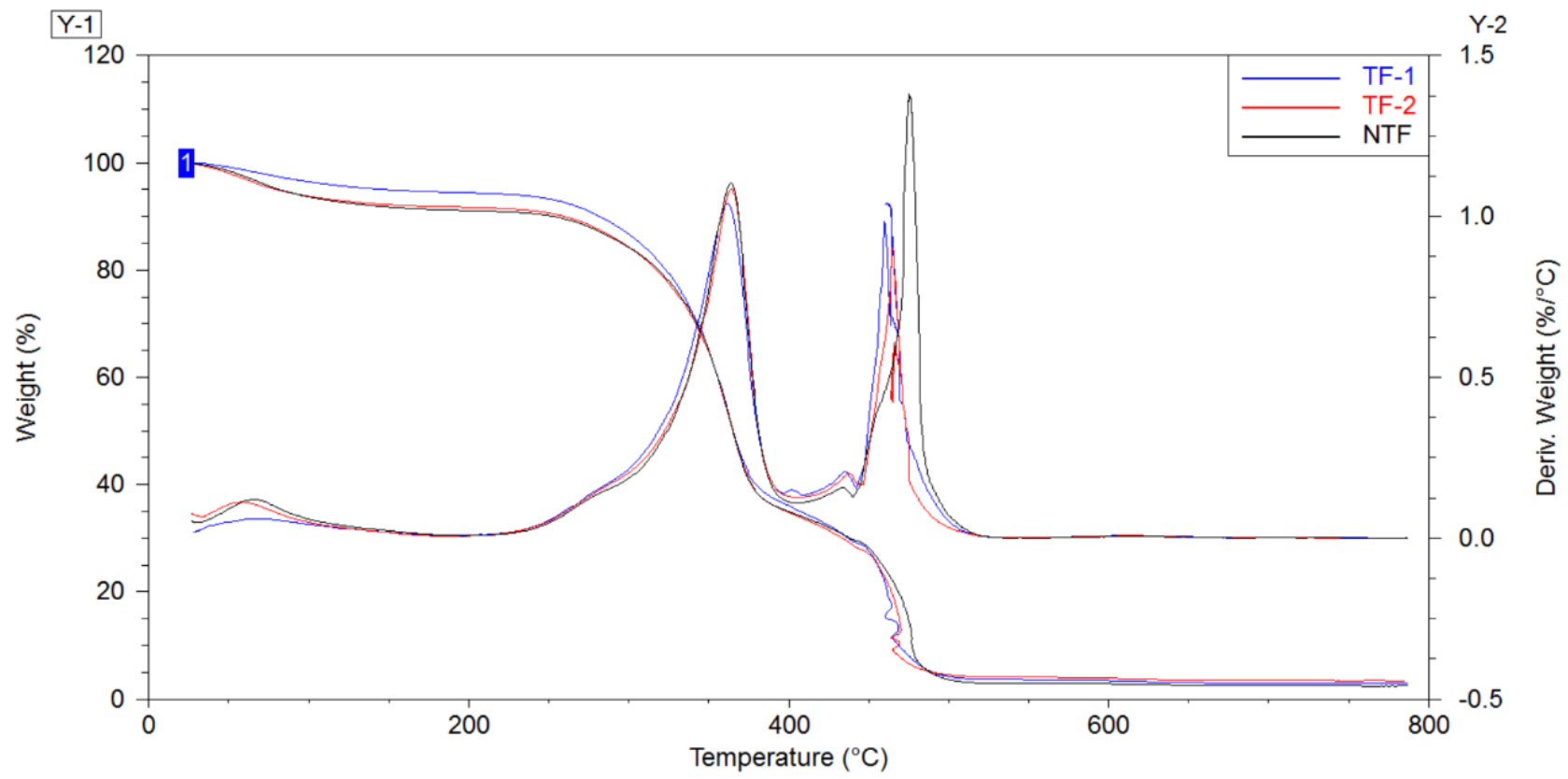

Figure 4 TGA thermograms and DTG curves of hemp fibres before (NTF) and after sc- $\mathrm{CO}_{2}$ treatment (TF-1 and TF-2). 


\subsection{Tensile properties}

The mechanical properties of the fibres from NTF, TF-1 and TF-2 were evaluated by tensile tests at a temperature of $20^{\circ} \mathrm{C}$ and $32 \%$ of relative humidity. The average tensile properties and their standard deviations are shown in Tab. 1. Their statistical distributions (Fig. 5) lead to an accurate assessment of the effect of the treatment on the tensile properties. The experimental data were correctly represented by Lognormal and Weibull distributions. For NTF, the average apparent tangent modulus was equal to approximately $19 \mathrm{GPa}, 374 \mathrm{MPa}$ for the tensile strength and $2.5 \%$ for the strain at failure. These values were on the same order of magnitude of those already reported in the literature, considering the same range of fibre diameter [20]. When compared to the properties of NTF, it can be concluded that the treatment induces a significant decrease in the tensile properties. A loss of approximately $43 \%$ and $30 \%$ are measured on the rigidity, for TF-1 and TF-2 respectively, as well as a loss of $47 \%$ and $40 \%$ in strength, $19 \%$ and $16 \%$ in strain at failure. It can also be underlined that the second treatment (TF-2) which is more aggressive than the first one, does not result in a more marked decrease in tensile properties. Further studies would be useful to refine the potential relationship between the process parameters and the resulting tensile properties.

It has also to be underlined that the fibres tested in the three batches were selected in a narrow diameter range (mean diameter of approximately $20 \mu \mathrm{m}$ ) to avoid any diameter effect in the comparison of the results. Taking into account the effect of the treatment on the fibre fineness, it is probable that a sampling representative of the diameter range of the different batches would have resulted in a different conclusion.

Table 1 Tensile properties of $\mathrm{CO}_{2}$ treated hemp fibres

\begin{tabular}{|c|c|c|c|c|c|c|}
\hline \multirow{2}{*}{$\begin{array}{l}\text { Tensile } \\
\text { properties }\end{array}$} & \multicolumn{2}{|l|}{ NTF } & \multicolumn{2}{|l|}{ TF-1 } & \multicolumn{2}{|l|}{ TF-2 } \\
\hline & $\begin{array}{l}\text { Mean } \pm \text { SD } \\
\text { Min...Max }\end{array}$ & $\begin{array}{l}\text { Distribution } \\
\text { Law }\end{array}$ & $\begin{array}{l}\text { Mean } \pm \text { SD } \\
\text { Min...Max }\end{array}$ & $\begin{array}{l}\text { Distribution } \\
\text { Law }\end{array}$ & $\begin{array}{l}\text { Mean } \pm \text { SD } \\
\text { Min...Max }\end{array}$ & $\begin{array}{l}\text { Distribution } \\
\text { Law }\end{array}$ \\
\hline $\mathrm{E}(\mathrm{GPa})$ & $\begin{array}{l}19.2 \pm 12.9 \\
3.5 \ldots 58.3\end{array}$ & $\begin{array}{l}\log \mathrm{N}(\mu, \lambda) \\
2.74,0.67\end{array}$ & $\begin{array}{l}11.0 \pm 6.9 \\
0.7 \ldots 35.5\end{array}$ & $\begin{array}{l}\log \mathrm{N}(\mu, \lambda) \\
2.16,0.76\end{array}$ & $\begin{array}{l}13.5 \pm 8.9 \\
1.1 \ldots 41.3\end{array}$ & $\begin{array}{l}\log \mathrm{N}(\mu, \lambda) \\
2.35,0.77\end{array}$ \\
\hline$\sigma_{\mathrm{R}}(\mathrm{MPa})$ & $\begin{array}{l}374 \pm 215 \\
77 \ldots 934\end{array}$ & $\begin{array}{l}\log \mathrm{N}(\mu, \lambda) \\
5.75,0.62\end{array}$ & $\begin{array}{l}197 \pm 93 \\
60 \ldots 470\end{array}$ & $\begin{array}{l}\log \mathrm{N}(\mu, \lambda) \\
5.18,0.44\end{array}$ & $\begin{array}{l}226 \pm 155 \\
57 \ldots 752\end{array}$ & $\begin{array}{l}\log \mathrm{N}(\mu, \lambda) \\
5.23,0.61\end{array}$ \\
\hline$\varepsilon_{\mathrm{R}}(\%)$ & $2.51 \pm 1.20$ & Weibull $(\alpha, \beta)$ & $2.03 \pm 1.39$ & Weibull $(\alpha, \beta)$ & $2.12 \pm 1.00$ & Weibull $(\alpha, \beta)$ \\
\hline
\end{tabular}




\begin{tabular}{|l|l|c|l|c|l|c|}
\hline & $0.57 \ldots 5.73$ & $2.29,2.74$ & $0.33 \ldots 6.84$ & $2.04,2.15$ & $0.85 \ldots 4.89$ & $2.49,2.32$ \\
\hline $\begin{array}{l}\text { Diameter } \\
(\mu \mathrm{m})\end{array}$ & $20.87 \pm$ & $/$ & $20.48 \pm$ & $/$ & $19.87 \pm$ & $/$ \\
\hline
\end{tabular}



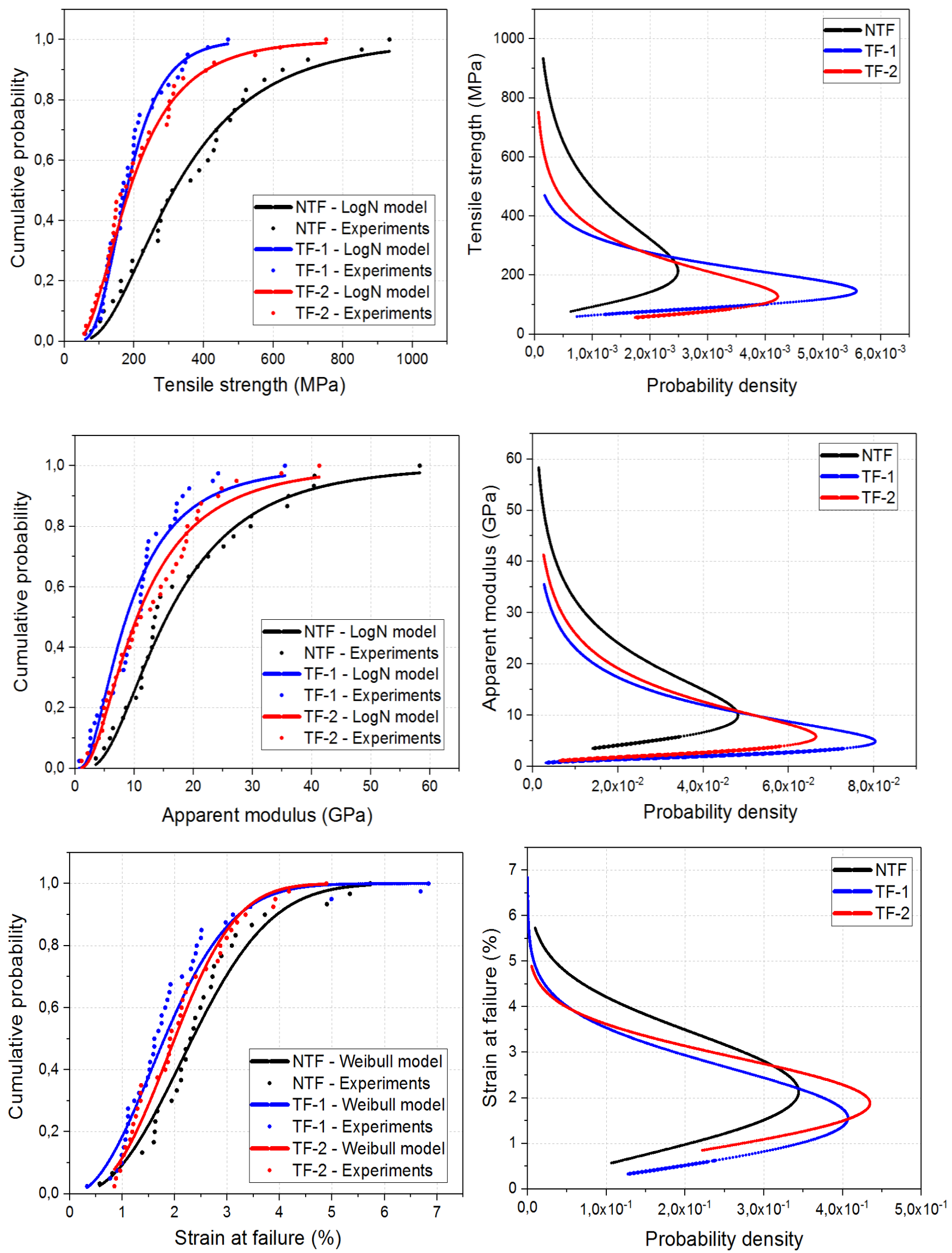

Figure 5 Probability density and cumulative distribution functions of the tensile properties 


\subsection{Hygroscopic behaviour of fibres}

The water vapour sorption isotherms of the fibre samples NTF, TF-1 and TF-2 are presented in Fig. 6. As already noted in the literature, the adsorption and desorption curves have a hysteretic behaviour and a sigmoid shape [21]. This nonlinearity results from the combination of different sorption mechanisms. The first zone $(0-15 \% \mathrm{RH})$ corresponds to the adsorption of a molecular monolayer. The second zone (15-70\% RH) refers to the adsorption of molecular multilayers and the third domain (70-100\% RH) is generally attributed to capillary condensation.

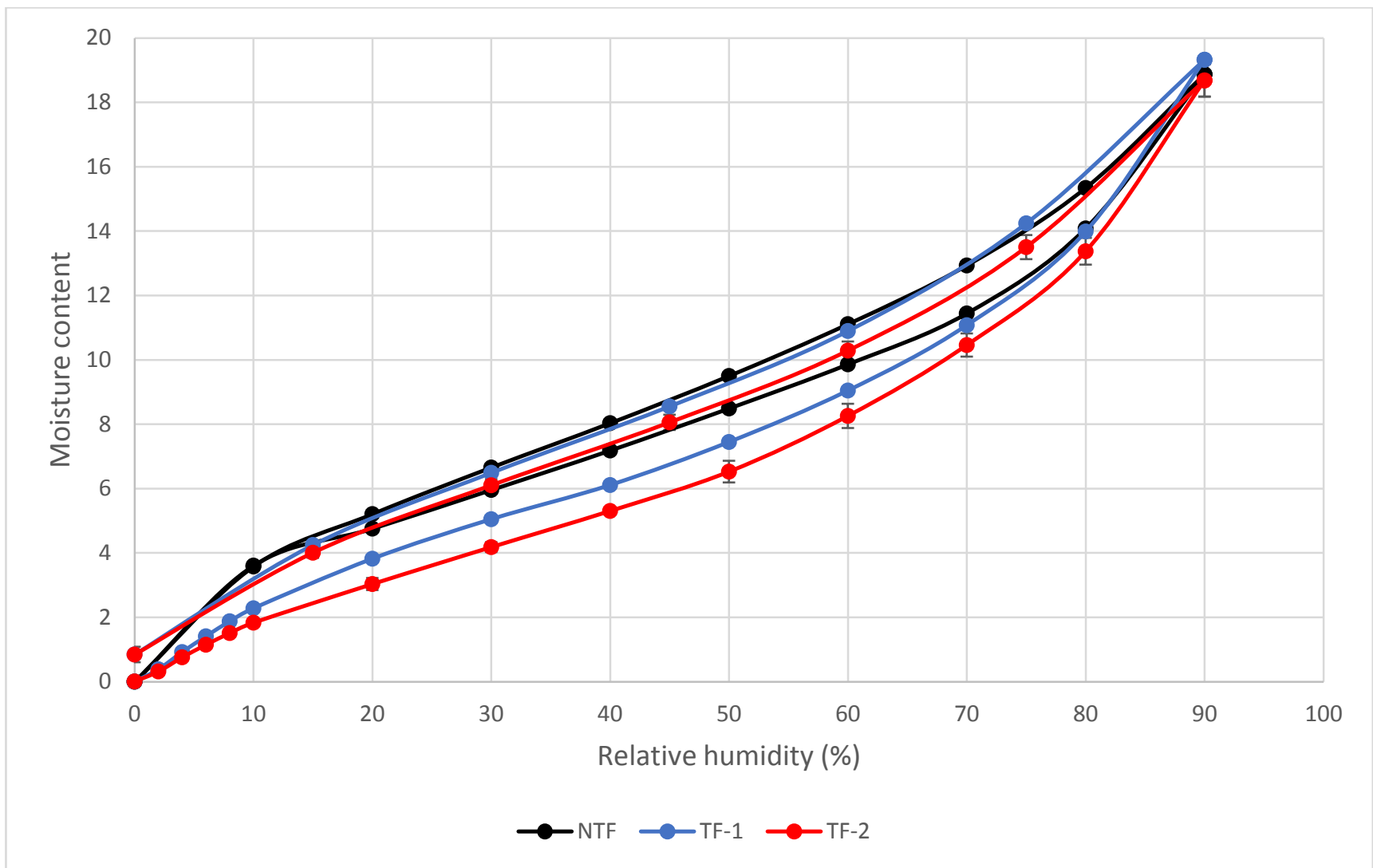

Figure 6 Water vapour sorption and desorption isotherms

A down shift of the isotherms of TF-1 and TF-2 compared with NTF was observed. At $50 \% \mathrm{RH}$ during the absorption, there was a $13 \%$ and $24 \%$ decline in the equilibrium moisture content (EMC) when compared to NTF, for TF-1 and TF-2 respectively. At $50 \% \mathrm{RH}$, the significant decrease in EMC for TF-2 is greater than the one measured on flax fibres treated under autoclave [24], for example. It illustrates the good efficiency of 
the sc- $\mathrm{CO}_{2}$ treatment to alleviate the hygroscopic capacity of hemp fibres when compared to other treatment processes proposed in literature. The reduction of the moisture sensitivity of the treated fibres reflects a decrease in the available hydroxyl groups at their surface and in their wall. This decrease was quantified using the Hailwood Horrobin model (HH model) [25]. The experimental sorption isotherm curves were fitted using the $\mathrm{HH}$ model and the parameter values identified by inverse method (minimizing algorithm). The identified values are presented in Tab. 2. The difference between treated and non-treated fibres is mainly on the $\mathrm{K}_{1}$ equilibria constant and $\mathrm{M}_{0}$ parameter. $\mathrm{K}_{1}$ is the constant between hydrate and dissolved water. $\mathrm{M}_{0}$ is a specific property related to the moisture sorption of the materials. It indicates the MC corresponding to all available sorption sites totally occupied by water molecules in the monolayer [26]. A decrease of $6.6 \%$ and $10.3 \%$ of $\mathrm{M}_{0}$ is observed compared to NTF, for TF-1 and TF-2 respectively. This is directly attributed to the reduction of the number of available hydroxyl groups.

Table 2 Hailwood Horrobin fitting parameters

\begin{tabular}{|c|c|c|c|c|c|c|c|}
\hline $\begin{array}{c}\text { HH } \\
\text { parameters }\end{array}$ & $\mathbf{A}$ & $\mathbf{B}$ & $\mathbf{C}$ & $\mathbf{K 1}$ & $\mathbf{K 2}$ & $\mathbf{W}$ & $\begin{array}{c}\mathbf{M}_{\mathbf{0}} \\
\mathbf{( 1 8 0 0 / W )}\end{array}$ \\
\hline NTF & 1.597 & 0.1619 & 0.00141 & 13.58 & 0.806 & 337.8 & 5.33 \\
\hline TF-1 & 2.960 & 0.1516 & 0.00146 & 7.17 & 0.830 & 361.3 & 4.98 \\
\hline TF-2 & 4.468 & 0.134 & 0.00145 & 4.56 & 0.844 & 376.6 & 4.78 \\
\hline
\end{tabular}

The moisture absorption curves (moisture content as a function of time) were also plotted and analysed. Fig. 7 presents the absorption curves recorded when the fibres were exposed to a change in $\mathrm{RH}$ from 10 to $20 \%, 40$ to $50 \%$ and 60 to $70 \% \mathrm{RH}$, respectively. When compared to the sorption isotherms which give information on EMC, the moisture absorption curves provide more information related to the sorption and diffusion kinetics. At $20 \% \mathrm{RH}$, the moisture uptake of NTF is largely higher than the one for TF-1 and TF-2. A slight delaying effect is also observed. When vapour concentration increases (for RH above 70\%), the treated fibres batches absorbed as high or higher water content than NTF. In this zone (70-100 RH), water molecules form clusters of large sizes and capillary condensation can occur. For treated fibres, the extraction of polysaccharides and lignin can increase the distance between the chains 
within the cell wall, and thus increase the void volume content. It could facilitate the water clustering and capillary condensation.

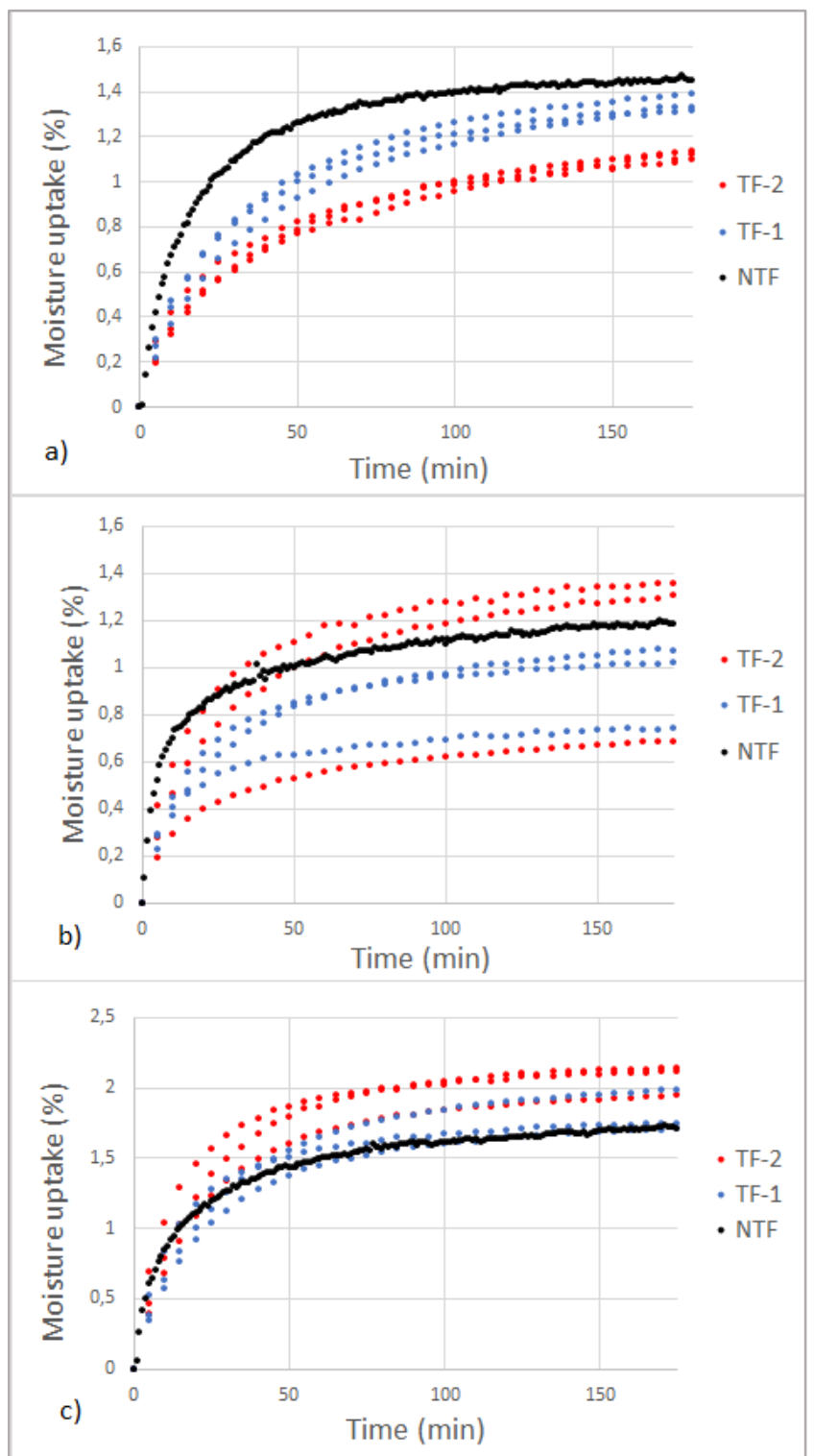

Figure 7 Sorption kinetics profile for NTF, TF-1 and TF-2. a) 10-20\% RH, b) 40-50\% RH and c) 60$70 \% \mathrm{RH}$

3.6 Chemical composition and ultrastructure analysis

The chemical composition of treated and non-treated hemp fibres analysed herein, is presented in Fig. 8 and Tab. 3 Total carbohydrate and Klason lignin contents were determined (Tab. 3). The NTF batch contained $80.9 \%$ of carbohydrates and $4.9 \%$ of 
Klason lignin as relative percentage of dry matter. These values agreed with those given by the literature [3].

Table 3 Carbohydrate and Klason lignin contents of the fibres expressed as percentage of dry matter

\begin{tabular}{|l|c|c|c|}
\hline & NTF & TF-1 & TF-2 \\
\hline Total carbohydrate content & $80.9 \pm 0.5$ & $78.9 \pm 0.7$ & $75.0 \pm 3.9$ \\
\hline Klason Lignin & $4.90 \pm 0.2$ & $3.97 \pm 0.11$ & $3.70 \pm 0.02$ \\
\hline
\end{tabular}

The sc- $\mathrm{CO}_{2}$ treatment affected the chemical composition of fibres. Indeed, the variation of total carbohydrate content between the batches NTF/TF-1 and NTF/TF-2 suffered a decrease of $2.5 \%$ and $7.3 \%$ respectively. Regarding Klason lignin relative content, we noticed a reduction of $19 \%$ and $24.5 \%$ for TF-1 and TF-2 respectively, compared with NTF. The variations are only statistically significant for the lignin content. Statistical tests indicated a $\mathrm{P}$ value higher than 0.05 for all the comparisons between the different batches except for the correlation of the lignin content between NTF and TF-2 characterized by a $\mathrm{P}$ value equal to 0.03 . The total carbohydrate content was not the most useful indicator therefore the content of monosaccharides (fucose, arabinose, rhamnose, galactose, xylose, mannose, galacturonic acid, glucuronic acid, glucose) was also quantified (Fig. 8). The major monosaccharide contained in hemp fibres was glucose (Glc). Glucose and cellulose are often wrongly assimilated. The other minor monosaccharides (with respect to mass) are related to pectins and hemicelluloses. The proportion of each type of carbohydrate declined with the $\mathrm{sc}-\mathrm{CO}_{2}$ treatment but at different rates. The three monosaccharides whose changes in relative content were the most important (around 30\% of decrease) were rhamnose (Rha), galacturonique acid (GalA) and xylose (Xyl). Rha and GalA are the main component of pectin, whereas Xyl is generally associated to hemicellulose. The sc- $\mathrm{CO}_{2}$ treatment predominately extracted lignin, hemicellulose and pectin. Except carbohydrates, lignin and water, hemp fibres are composed of other non-quantified products. There are lipid compounds, proteins and minerals. It is not possible to evaluate easily the effect of the treatment on these components. However, the $\mathrm{C} / \mathrm{N}$ (Carbon/Nitrogen) ratio provides part of the answer concerning the variation of proteins content. It was not subject to significant variation since it was equal to 120 for NTF, 129 for TF-1 and 127 for TF-2. So, proteins were 
not significantly affected by the sc- $\mathrm{CO}_{2}$ process. Furthermore, as this work reported a decrease of the proportion of carbohydrates and Klason lignin content, a possible explanation for the remaining proportion of the fibres' components is that it corresponds to non-quantified compounds such as lipids, proteins and minerals.

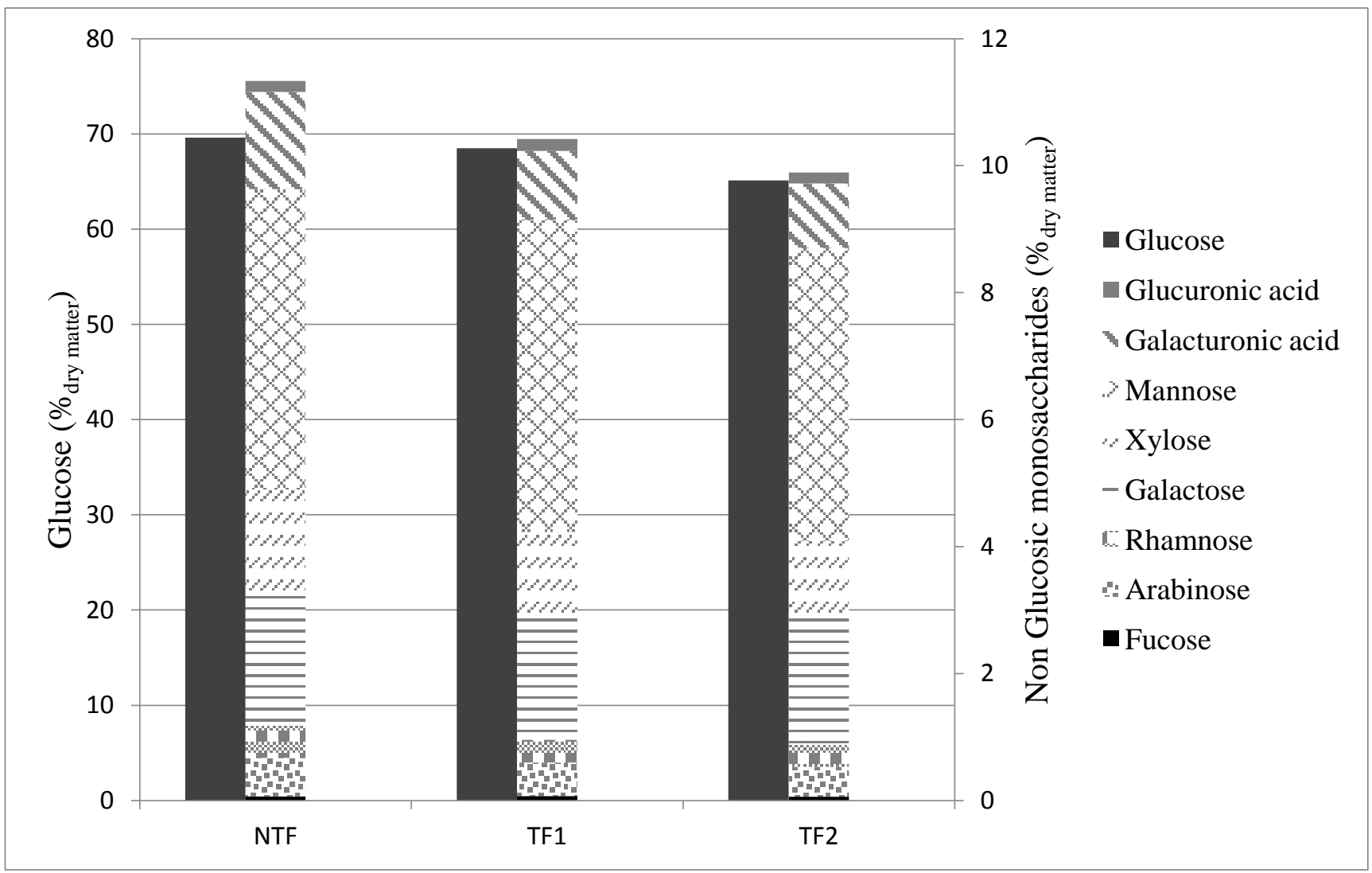

Figure 8 Relative contents of monosaccharides in treated and non-treated fibres. Fuc fucose, Ara arabinose, Rha rhamnose, Gal galactose, Xyl xylose, Man mannose, GalA galacturonic acid, GlcA glucuronic acid, Glu glucose

The results from the XRD analysis revealed a slight decrease of the crystalline part of the cellulose from $78.8 \%$ for NTF to $76.8 \%$ for TF-2. These orders of magnitude are in good accordance with values reported in the literature for hemp fibres ranging from $60 \%$ to $88 \%[20,27]$.

\subsection{Analysis of VOCs by SPME-GC-MS}

The gas sample analysed when relieving pressure of the reactor highlighted the presence of fatty acids, identified as $n$-hexadecanoic acid and $n$-decanoic acid, with a probability of $83 \%$ and $77 \%$, respectively. 


\section{Discussion}

The results described above reveal three major effects of the $\mathrm{sc}-\mathrm{CO}_{2}$ treatment on hemp fibres.

The first is the significant increase in the fibre fineness and cleanness. The $\mathrm{sc}-\mathrm{CO}_{2}$ treatment promotes clearly the inter-fibre decohesion and thus the separation of the individual fibres within the technical fibres. Indeed, the morphological analysis indicated a higher proportion of fibres whose diameter was between $5 \mu \mathrm{m}$ and $21 \mu \mathrm{m}$ (corresponding to single primary or secondary fibres or bundles of secondary fibres). This is mainly explained by the extraction of the substances responsible for the cohesion of single fibres together, i.e, pectins (present in the middle lamella) and lignin.

The second major result is the reduction of the moisture sensitivity. The $\mathrm{sc}-\mathrm{CO}_{2}$ treatment induces a significant decrease in the EMC and also a slowdown of moisture diffusion when fibres are exposed to $\mathrm{RH}$ inferior to $70 \%$. This decrease in moisture absorption is also directly linked to the modification of the biochemical composition and organisation of the fibre wall. Polysaccharides such as hemicellulose and pectin within the fibre wall possess numerous hydroxyl groups, which impart predominantly to the fibre its hydrophilic character. Chemical analysis showed a decrease of the monosaccharides GalA, Rha and Xyl, that are the main components of pectin and hemicellulose, after the sc- $\mathrm{CO}_{2}$ treatment. The process was able to extract enough carbohydrates to make hemp fibres less sensitive to moisture, in particular in the sorption domain dominated by bound water (i.e. for $\mathrm{RH}$ inferior to $70 \%$ ). The $\mathrm{sc}-\mathrm{CO}_{2}$ induces a decrease in the number of available hydroxyl groups, which naturally diminish the monolayer water content. On the contrary, the changes in the polysaccharide structure and organisation and the possible increase in void volume result in a similar and even increased of the EMC in the third zone of the sorption isotherm (for RH above 70\%).

These properties enhancement (fibre individualisation, cleanness and moisture sensitivity reduction) were obtained while retaining a same thermal resistance. This later is an important issue, in particular when considering the composite manufacturing temperatures used for most of the current organic matrices (with a temperature ranging generally from $100^{\circ} \mathrm{C}$ to $200^{\circ} \mathrm{C}$ ). 
In contrast, the last significant effect is quite more negative. A significant decrease in the fibre rigidity as well as a more brittle fracture were pointed out for treated fibres when compared to NTF. This loss in tensile properties can be explained by the slight disordering of cellulose (revealed by the slight decrease in crystallinity index) and the partial degradation of hemicellulose and pectin, which certainly play a role in the architecture of the cell wall. Although no defects on the external surface of fibres were observed on SEM images, it can also be hypothesised that the treatment, and more exactly the depressurization step and the potential associated shock, induces defects and/or porosities within the fibre cell wall. These defects could explain the strong decrease in tensile strength and are consistent with the increase in EMC observed when exceeding 70\% RH. Interestingly, despite a more significant removal of constituents, the second treatment (TF-2) did not result in a more marked decrease in tensile properties. Thus, the decrease in tensile properties could be mainly driven by the induced physical effect rather than by the change in biochemical composition.

Therefore, even if the sc- $\mathrm{CO}_{2}$ treatment implies positive effects on hemp fibres in view of their embedment in polymeric matrices as above mentioned, it also induces a decrease in tensile strength and stiffness comprised between 30 and 50\% for the considered treatment parameters. This could have a substantially impact on the mechanical properties resulting at the composite scale.

So, the sc- $\mathrm{CO}_{2}$ fibre treatment still need to be optimised to tune its effect on these main inputs (fineness, cleanness, moisture sensitivity and tensile properties). Anyway, it is already a relevant option for composite families for which the aspect ratio is prevalent on the fibre tensile performance (such for short-fibre composites). As a matter of fact, some works pointed out that even if the treatment used to separate the fibres reduces the tensile properties of the fibres themselves, a significant increase in the properties at the composite scale can be observed thanks to the better individualisation of the fibres and also to a better cohesion at the fibre/matrix interface [28].

\section{Conclusions}

A sc- $\mathrm{CO}_{2}$ treatment was performed on industrial hemp fibres and some of their properties were significantly modified. This innovative "green" process allowed the improvement of the fibre cleaning and refinement and the decrease of their moisture sensitivity, while retaining their thermal resistance. All these property modifications are strongly related to the extraction of polysaccharides and lignin. In the meantime, it also 
induces a decrease in the tensile rigidity of the fibre as well as a more brittle fracture. However, this variation does not compromise the use of the treated fibres for the development of composites. The benefits in terms of fibres fineness and moisture sensitivity are results in favour of the use of the $\mathrm{sc}-\mathrm{CO}_{2}$ treatment for composites applications, whereas the decrease of the mechanical properties is a real hurdle to the development of treated hemp fibre composites. This sc- $\mathrm{CO}_{2}$ process may be extended to different plant fibres. The treatment conditions herein reported have also to be optimized in order to improve the properties of the fibres and current works are focused on the characterization of fibre/matrix interface.

\section{Acknowledgements}

The authors are grateful for general and financial support from the Centre National de la Recherche Scientifique (CNRS-France) and the University of Bourgogne Franche-Comté. C.F. is thankful for a PhD fellowship awarded by the Conseil Régional de Bourgogne (France) in the frame of the "Jeunes Chercheurs Entrepreneurs-2016" program. 


\section{References}

1. Mohanty AK, Misra M, Drzal LT (2005) Natural fibers, biopolymers, and biocomposites. Taylor \& Francis, Boca Raton, FL

2. Pickering KL, Efendy MGA, Le TM (2016) A review of recent developments in natural fibre composites and their mechanical performance. Compos Part Appl Sci Manuf 83:98-112. https://doi.org/10.1016/j.compositesa.2015.08.038

3. Liu M, Thygesen A, Summerscales J, Meyer AS (2017) Targeted pre-treatment of hemp bast fibres for optimal performance in biocomposite materials: A review. Ind Crops Prod 108:660-683. https://doi.org/10.1016/j.indcrop.2017.07.027

4. Coroller G, Lefeuvre A, Le Duigou A, et al (2013) Effect of flax fibres individualisation on tensile failure of flax/epoxy unidirectional composite. Compos Part Appl Sci Manuf 51:62-70. https://doi.org/10.1016/j.compositesa.2013.03.018

5. Rask M, Madsen B, Sørensen BF, et al (2012) In situ observations of microscale damage evolution in unidirectional natural fibre composites. Compos Part Appl Sci Manuf 43:1639-1649. https://doi.org/10.1016/j.compositesa.2012.02.007

6. Placet V, Méteau J, Froehly L, et al (2014) Investigation of the internal structure of hemp fibres using optical coherence tomography and Focused Ion Beam transverse cutting. J Mater Sci 49:8317-8327. https://doi.org/10.1007/s10853-014-8540-5

7. Charlet K, Béakou A (2011) Mechanical properties of interfaces within a flax bundle - Part I: Experimental analysis. Int J Adhes Adhes 31:875-881. https://doi.org/10.1016/j.ijadhadh.2011.08.008

8. Dhakal H, Zhang Z, Richardson M (2007) Effect of water absorption on the mechanical properties of hemp fibre reinforced unsaturated polyester composites. Compos Sci Technol 67:1674-1683. https://doi.org/10.1016/j.compscitech.2006.06.019

9. Le Duigou A, Davies P, Baley C (2009) Seawater ageing of flax/poly(lactic acid) biocomposites. Polym Degrad Stab 94:1151-1162. https://doi.org/10.1016/j.polymdegradstab.2009.03.025

10. Pucci MF, Liotier P-J, Seveno D, et al (2017) Wetting and swelling property modifications of elementary flax fibres and their effects on the Liquid Composite 
Molding process. Compos Part Appl Sci Manuf 97:31-40.

https://doi.org/10.1016/j.compositesa.2017.02.028

11. Peach J, Eastoe J (2014) Supercritical carbon dioxide: a solvent like no other. Beilstein J Org Chem 10:1878-1895. https://doi.org/10.3762/bjoc.10.196

12. Zhang X, Heinonen S, Levänen E (2014) Applications of supercritical carbon dioxide in materials processing and synthesis. RSC Adv 4:61137-61152. https://doi.org/10.1039/C4RA10662H

13. Schmidt A, Bach E, Schollmeyer E (2002) Damage to natural and synthetic fibers treated in supercritical carbon dioxide at 300 bar and temperatures up to $160^{\circ} \mathrm{C}$. Text Res J 72:1023-1032

14. De Magalhaes Nunes Da Pontee MLDMND, Da Silva Lopes JA, Vesna N-V, et al (2010) Method for direct treatment of cork stoppers, using supercritical fluids

15. Daza Serna LV, Orrego Alzate CE, Cardona Alzate CA (2016) Supercritical fluids as a green technology for the pretreatment of lignocellulosic biomass. Bioresour Technol 199:113-120. https://doi.org/10.1016/j.biortech.2015.09.078

16. Attard TM, Bainier C, Reinaud M, et al (2018) Utilisation of supercritical fluids for the effective extraction of waxes and Cannabidiol (CBD) from hemp wastes. Ind Crops Prod 112:38-46. https://doi.org/10.1016/j.indcrop.2017.10.045

17. Patil PD, Dandamudi KPR, Wang J, et al (2018) Extraction of bio-oils from algae with supercritical carbon dioxide and co-solvents. J Supercrit Fluids 135:60-68. https://doi.org/10.1016/j.supflu.2017.12.019

18. Gutiérrez MC, Rosa P de TV e, De Paoli M-A, Felisberti MI (2012) Biocompósitos de acetato de celulose e fibras curtas de Curauá tratadas com CO2 supercrítico. Polímeros 22:295-302. https://doi.org/10.1590/S010414282012005000037

19. 张华, 张建春, 郝新敏 (2009) Degumming method of hemp fiber

20. Placet V, Day A, Beaugrand J (2017) The influence of unintended field retting on the physicochemical and mechanical properties of industrial hemp bast fibres. $\mathrm{J}$ Mater Sci 52:5759-5777. https://doi.org/10.1007/s10853-017-0811-5 
21. Hill CAS, Norton A, Newman G (2009) The water vapor sorption behavior of natural fibers. J Appl Polym Sci 112:1524-1537.

https://doi.org/10.1002/app.29725

22. Placet V, Trivaudey F, Cisse O, et al (2012) Diameter dependence of the apparent tensile modulus of hemp fibres: A morphological, structural or ultrastructural effect? Compos Part Appl Sci Manuf 43:275-287.

https://doi.org/10.1016/j.compositesa.2011.10.019

23. Martin N, Mouret N, Davies P, Baley C (2013) Influence of the degree of retting of flax fibers on the tensile properties of single fibers and short fiber/polypropylene composites. Ind Crops Prod 49:755-767. https://doi.org/10.1016/j.indcrop.2013.06.012

24. Alix S, Colasse L, Morvan C, et al (2014) Pressure impact of autoclave treatment on water sorption and pectin composition of flax cellulosic-fibres. Carbohydr Polym 102:21-29. https://doi.org/10.1016/j.carbpol.2013.10.092

25. Hailwood AJ, Horrobin S (1946) Absorption of water by polymers: analysis in terms of a simple model. Trans Faraday Soc 42:B084. https://doi.org/10.1039/tf946420b084

26. Li T, Cheng D, Avramidis S, et al (2017) Response of hygroscopicity to heat treatment and its relation to durability of thermally modified wood. Constr Build Mater 144:671-676. https://doi.org/10.1016/j.conbuildmat.2017.03.218

27. Thygesen A, Oddershede J, Lilholt H, et al (2005) On the determination of crystallinity and cellulose content in plant fibres. Cellulose 12:563-576. https://doi.org/10.1007/s10570-005-9001-8

28. Li Y, Pickering KL (2008) Hemp fibre reinforced composites using chelator and enzyme treatments. Compos Sci Technol 68:3293-3298.

https://doi.org/10.1016/j.compscitech.2008.08.022 